\title{
Introducing the XtaLAB Synergy Flow
}

\author{
M D Campo ${ }^{1}$, Joseph Ferrara ${ }^{2}$, Pierre Le Magueres ${ }^{3}$, Mathias Meyer ${ }^{4}$, Pezemyslaw Stec ${ }^{5}$, Damian \\ Kucharczyk ${ }^{6}$, Mateusz Idzi ${ }^{7}$, Michal Jasnowski ${ }^{8}$, Marcin Grzesczyk ${ }^{9}$, Artur Wisniewski ${ }^{10}$ \\ ${ }^{1}$ Life Sciences, Rigaku Americas Corporation ${ }^{2}$ Rigaku Americas Corp, ${ }^{3}$ Rigaku Americas Corp, \\ ${ }^{4}$ Rigaku Polska Sp. zo.o. ${ }^{5}$ Rigaku Polska, ${ }^{6}$ Rigaku Polska, ${ }^{7}$ Rigaku Polska, ${ }^{8}$ Rigaku Polska, ${ }^{9}$ Rigaku \\ Polska, ${ }^{10}$ Rigaku Polska \\ mark.delcampo@rigaku.com
}

The XtaLAB Synergy Flow turns any Synergy cabinet diffractometer into an automated, high-throughput machine by incorporating a 6-axis UR3 Universal Robot and a 3-puck dewar. The Flow system can automatically screen and collect 48 crystal samples with minimal human intervention. CrysAlisPro has been upgraded with tools to control all aspects of robotics and sample queuing. A unique X-ray safe dewar-drawer system allows loading and unloading of pucks without opening the X-ray enclosure or disturbing data collection. Ultimately, the XtaLAB Synergy Flow system is the perfect solution to allow full-time use of your diffractometer during a time when human interaction and contamination must be minimized.

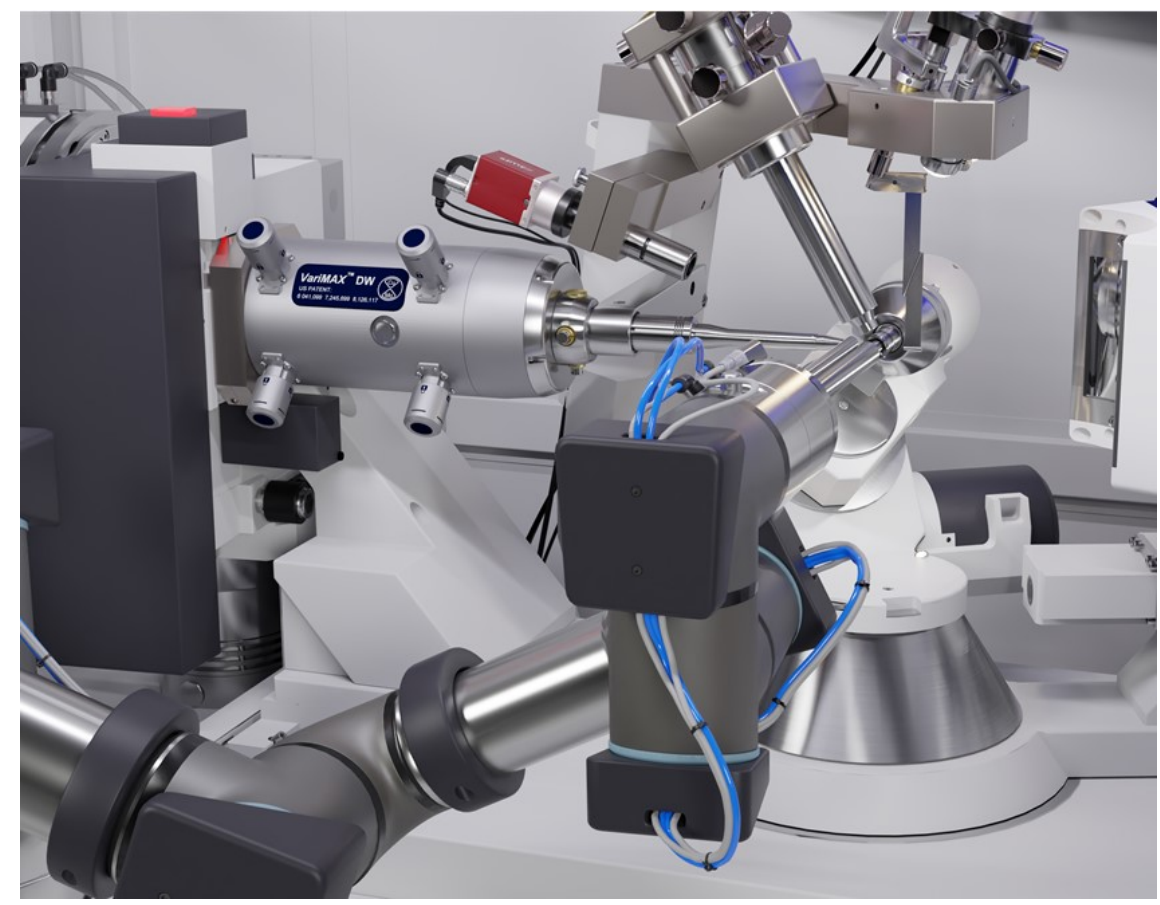

Figure 1 